This is a self-archived version of an original article. This version may differ from the original in pagination and typographic details.

Author(s): Ruutiainen, Ville; Alasuutari, Maarit; Karila, Kirsti

Title: Rationalising public support for private early childhood education and care : the case of Finland

Year: 2020

Version: Accepted version (Final draft)

Copyright: @ 2019 Informa UK Limited, trading as Taylor \& Francis Group

Rights: In Copyright

Rights url: http://rightsstatements.org/page/InC/1.0/?language=en

Please cite the original version:

Ruutiainen, V., Alasuutari, M., \& Karila, K. (2020). Rationalising public support for private early childhood education and care : the case of Finland. British Journal of Sociology of Education, 41(1), 32-47. https://doi.org/10.1080/01425692.2019.1665497 


\title{
Rationalising Public Support for Private Early Childhood Education and Care: The Case of Finland
}

\begin{abstract}
In Finland, early childhood education and care (ECEC) is traditionally publicly provided. However, private ECEC provision has increased during the past decade, largely as a result of financial support from the public sector. Drawing on qualitative interviews with municipal decision-makers, this article identifies three frames within which publicly subsidised private ECEC provision and marketisation is rationalised: the pragmatic frame, government frame and choice frame. The results show that even though market logics and tendencies seem to have gained a strong foothold in local policies, there is a keen interest in universalism and maintaining public control over local ECEC provision.
\end{abstract}

Keywords: early childhood education and care, marketisation, Nordic countries, choice, public subsidies

\section{Introduction}

Finland is conceived of as a part of the Nordic educational regime (West \& Nikolai, 2013), and most early childhood education and care (ECEC) is publicly provided (author reference) and based on the idea of universalism (Kildal \& Kuhnle, 2005; Naumann, 2011). In that sense, Finnish and Nordic ECEC trajectories diverge from global ECEC pathways, which have been influenced by neoliberal ideas concerning effectiveness, competition and freedom of choice (e.g. Adamson \& Brennan, 2014; Akgunduz \& Plantega, 2014; Penn, 2011, 2012; Vanderbroeck, 2006). This is especially true in liberal English-speaking countries where market-oriented ECEC often comprises a substantial part of ECEC provision (see Penn, 2012). However, 'Nordic countries have edged toward a neoliberal free choice model', relying on the co-existence of a regulated private sector and substantially larger subsidised public ECEC provision (Mahon, Anttonen, Bergqvist, Brennan, \& Hobson, 2012). In Finland, this has been particularly prevalent during the last decade, with municipalities being key actors. In this article, we will illuminate how municipal politicians and administrators view the recent development in the provision of ECEC in Finland.

Traditionally, publicly subsidised private ECEC provision in Finland has involved only small, local for-profit entrepreneurs and non-profit agents. In 2000, the share of private ECEC services was roughly $11 \%$ (Säkkinen \& Kuoppala, 2017). Since the enforcement of the Act on Service Vouchers in Social Welfare and Health, AoSV (569/2009) in 2009, many municipalities have begun to provide ECEC vouchers for families. As a result, the private ECEC sector has expanded especially during the past decade, and now accounts for $17 \%$ of all ECEC provision (Säkkinen \& Kuoppala, 2017). At the same time, private provision has become more diverse because large national and multinational for-profit companies have begun to provide ECEC services in many municipalities. Public demand-side subsidies, 
especially those granted by municipalities, have enabled the expansion of the private sector. These developments differentiate ECEC provision from the provision of primary and secondary education, which is almost exclusively a public responsibility and protected from profit interests.

In this article, we draw on expert interviews to examine how municipal politicians and administrators view the growth of private ECEC provision and public support for ECEC in Finland. Overall, issues related to the marketisation of ECEC are widely discussed in the literature (e.g. Adamson \& Brennan, 2014; Akgunduz \& Plantega, 2014; Brennan, Cass, Himmelweit, \& Szebehely, 2012; Lewis \& West, 2016; Lloyd \& Penn, 2014; Moss, 2009; Penn, 2000, 2011; Vincent, Braun \& Ball, 2008). However, recent developments in Finland have gone without significant scientific interest. The evolution of the Finnish ECEC system is, though, linked with international trends (author reference). Therefore, an examination of recent local-level developments in the Finnish context also offers an interesting perspective on the marketisation of ECEC in the Nordic welfare and education regimes and more broadly.

\section{The Marketisation of ECEC}

The current era of globalization is characterized by intense marketisation, including the promotion of market ideology and market-based reforms (Djelic, 2006). Many countries have turned to market mechanisms for the provision of ECEC and other welfare services (Adamson \& Brennan, 2014).

Marketisation is seen as a manisfestation of neo-liberal policy (see Vanderbroeck, 2006) and its austerity measures (Schwiter, Berndt \& Truong, 2015), or as a form of the economisation of society (Çalışkan \& Callon, 2010). Marxist theory of modern society argues that this is a logical and understandable process because of the preponderance of the capitalist economy over other sectors of society. According to this view, economisation is constantly present in capitalist societies (Schimank \& Volkmann, 2012). Foucault-inspired thinking points out that marketisation penetrates every aspect of the state and its institutions in neo-liberal (especially ordoliberal) societies, since the markets are tied to government (Gane, 2012). Therefore, as Foucault $(2008,121)$ states, 'one must govern for the market, rather than because of the market'. Consequently, the state is no longer keeping an eye on the market, but it is rather guided by the market as it increasingly keeps an eye on itself (Gane, 2012).

Marketisation changes the way that the roles of the state and the individual are seen. In the context of education, this means that individuals and families must assume increasing responsibility for self-management etc. (Ozga, 2011). However, parents differ significantly in terms of their cultural and economic capital for making successful choices (Angus, 2015; Vincent et al 2008). Moreover, when education is treated as a commodity, its instrumental value is stressed at the expense of its intrinsic value (Brancaleone \& O’Brien, 2011).

In practice, marketisation can assume many different forms, including quasi-markets, contracting out, benchmarking and yardstick competition, and public-private collaboration 
(Hansen \& Lindholst, 2016). Markets can only exist by generating and reproducing distinctions between 'things' that are valued and 'agencies' valuing them (Çalışkan \& Callon, 2010). Although marketisation often includes service privatisation, this is not a necessary part of marketisation. Likewise, there can be privatisation without marketisation (Hansen \& Lindholst, 2016; Anttonen \& Meagher 2013). In the case of Finnish ECEC, both dimensions are present to some extent. Demand-side subsidies granted by the public sector both increase families' range of choices and give an incentive for private agents to start providing services.

In the ECEC context, marketisation may involve providing ECEC through a mixed economy of public, private non-profit and private for-profit providers (Lloyd \& Penn, 2014) or it may include the outsourcing of service provision to private providers and helping families to purchase such services (Adamson and Brennan, 2014). Briefly, the marketisation of childcare can be conceived of as government measures that authorise, support or enforce the introduction of markets, the creation of relationships between buyers and sellers or the use of market mechanisms to allocate care (Brennan et al., 2012). Hence, the marketisation of ECEC should be understood as political action (see Lewis \& West, 2016). Due to its political nature, the marketisation process is context-specific and path-dependent (Brennan et al., 2012), and it is shaped by the complex and meandering historical trajectories of the development of welfare states (Naumann, 2011).

The standard rationale for the marketisation of ECEC follows general market logic, which is based on the idea of rational customers choosing from many competitive service providers. The providers' competition is expected to increase the quality of services and guarantee such services' cost effectiveness. Markets should also reflect customers' various preferences and thus foster innovativeness and flexibility in service provision. Shortages, related to unsatisfactory services, will lead to market-based corrections. Thus, markets are expected to be self-regulatory (e.g. Brennan et al., 2012; Moss, 2009; Naumann, 2011; Penn, 2009).

\section{The Finnish Context to Marketisation of ECEC}

In Finland, the provision of early education and childcare constitutes an integrated system. Municipalities are obligated to provide ECEC for all children from 0 to 6 years, regardless of parents' labour market status. Pre-primary education for 6-year-olds is an obligatory part of ECEC, and at the age of 7 years children start primary education. The ECEC system is mostly centre-based, but it also includes family day care. Families' income-tested ECEC fees in the public sector (0-290€) cover around 14\% of the municipalities' costs of ECEC provision (e.g. Vlasov 2018; FNAfE 2018; Act on ECEC 36/1973).

The governance of ECEC involves two levels. At the national level, ECEC provision and pedagogy are regulated by national legislation and normative core curriculum guidelines under the Ministry of Education and Culture. Municipalities, for their part, have a statutory responsibility for ECEC provision. However, they have the freedom to choose to provide ECEC services themselves, to purchase outsourced services or to provide them privately by subsidising demand. Municipal authorities also have the statutory duty to monitor private 
provision (FNAfE 2016; Act on ECEC 36/1973) ${ }^{1}$. Thus, public and private ECEC are likewise regulated by central and municipal governments. For example, private providers are obliged to comply with the national ECEC curriculum and national statutes regarding staff qualifications and child-adult ratios.

Private ECEC provision and families' ability to choose an ECEC provider are supported by demand-led subsidies granted by municipalities and the state. The municipalities can choose between a voucher system and a local private day care allowance (PDAMS) or use both. The municipality defines the monetary value of the ECEC voucher. The voucher enables the family to freely choose the private provider that they prefer, as long as the provider is approved by the municipality. The guidelines for voucher systems are laid down in legislation (AoSV 569/2009). Local authorities then conclude local voucher contracts that regulate private provision within their region. Vouchers are usually income-tested, and legislation requires that municipalities define their value so that it is 'reasonable' from the customer's perspective. In practice, voucher values are set in such a way that customer fees for families are relatively close to those in the public sector. The PDAMS combines the private childcare allowance (PDA), which is granted by the Social Insurance Institution and available for every family in Finland, and a municipal supplement (MS), which is paid by around 40\% of Finnish municipalities (Lahtinen \& Selkee, 2016). The PDA consists of fixed and income-tested components. The value of the municipal supplement varies by municipality and may be income-tested or fixed. In practice, due to the small size of plain PDA, the municipal supplement is always necessary in cases where the municipality decides to support centrebased ECEC with PDA. ${ }^{2}$

In 2016, among children attending centre-based ECEC or family day care, an ECEC voucher was granted to $7.5 \%$ of children, and a PDAMS was granted to $6.7 \%$ of children. Recently the use of vouchers has been increasing and the use of PDAMS decreasing (see Säkkinen \& Kuoppala 2017).

Theoretically, it can be presumed that the form of subsidy used in a given municipality has a dual effect on local ECEC markets. Firstly, public subsidies for private ECEC provision are believed to enhance the public sector's regulatory power (Wadsworth \& George, 2009). However, mainly because of the more explicit legislation and municipal control via local contracts, voucher-subsidised private provision can be expected to be more tightly regulated than services subsidised with PDAMS. Secondly, when the subsidy is income-tested, which is the case especially with vouchers, customer fees in the private sector are relatively close to those in the public sector. Fixed-sum subsidies, usually PDAMS, in turn, mean that the customer fee in the private sector is the same for every family. On this basis it may be assumed that income-tested subsidies should allow families in diverse financial situations to make use of private services, whereas fixed-sum subsidies favour middle class families who would have to pay the maximum fee in the public sector anyway.

\footnotetext{
${ }^{1}$ Municipalities' costs are covered by municipal taxes and government transfers, which cover around $25 \%$ of municipal spending (MoF 2018).

${ }^{2}$ Voucher values in different municipalities range typically from $371 €$ to $1,148 €$. Depending on parents' income, the value of PDA ranges from 173.74 to $319.85 €$ and MS from 100 to $860 €$ (Lahtinen \& Selkee 2016)
} 


\section{Data and Methods}

The data for the study are drawn from qualitative research interviews with municipal decisionmakers regarding ECEC that were conducted in 2016. To include the two key parties in municipal decision making related to ECEC policy, both local politicians and ECEC administrators were interviewed. Thus, the data consist of interviews with 18 politicians and 29 administrators in seven Finnish municipalities. The politicians represented parties that played both major and minor roles in the local policy of a given municipality. Nine interviewed politicians and two administrators were males. Each interviewee was personally invited to participate in the research. Participation was voluntary, and the interviewees were informed of their right to withdraw from the research at any stage in the process. All the interviewees signed an informed consent form. To protect the anonymity of the interviewees, only their positions (administrators/politicians) are described. The seven municipalities were located in different parts of the country, had diverse demographical features ${ }^{3}$ and had different policies regarding the demand-based subsidies they provided for private ECEC. Two of them provided only PDAMS, three provided both vouchers and PDAMS, and two provided only vouchers. The selection of the municipalities aimed to maximise the variation between them and thus increase the transferability of the findings (Gobo, 2004).

The interviews were carried out by a team of nine researchers, with each interview conducted by one researcher. The interviews, 90 minutes on average, ranged widely over ECEC provision, as well as system and service guidance, in a given municipality. We selected all the sections that related to public support for private ECEC or private ECEC provision more broadly for a closer analysis.

In the data analysis, we apply interpretative discourse analysis (DA) to scrutinise the social contexts at work and the discourse supporting them (see Phillips \& Hardy, 2002).

Interpretative discourse analysis examines multiple texts that 'constitute bodies of discourse' and thus seeks to identify discursive patterns and structures (Heracleous, 2004, p. 176). We use discourse as an analytical concept understood as a general system used to formulate and articulate ideas during a particular period of time (see Alvesson \& Karreman, 2000).

Discourses provide people with a range of resources to draw on and make sense of the world with (Potter, 2012; Potter \& Wetherell, 1995). While discourses themselves are constructions of the resources used, they can also be understood as constructive in the sense as they build or produce versions of the world, society and events (see Potter, 2004, 2012).

DA understands interview data as a form of accounting rather than factist reports about reality (Nikander, 2012). Thus, our analysis focused on how social reality was produced in the interviews and which available cultural resources were used in that process. Although both the interviewer and interviewee(s) act as agents and agenda setters in an interview situation and participate in the meaning-making process (see Nikander 2012), in this study we focus on the interviewees' accounts and discussion. At the beginning of the analysis, we scrutinised how the interviewees described public support for private ECEC and different

\footnotetext{
${ }^{3}$ The populations of the municipalities ranged from around 13,000 to 650,000 inhabitants.
} 
subsidy systems. Similarities and differences in the descriptions of the subsidy systems were identified. However, focusing on the discussion of the subsidies as such overlooked certain aspects of the descriptions of increased private ECEC provision. Therefore, the analysis was taken further to allow a more encompassing view of the connective and repetitive features of the descriptions and explanations related to subsidies for private ECEC. In the analysis we worked with the Finnish data. The interview extracts presented in this article were selected so that they were illustrative, and there were only minor challenges related to translation and contextual knowledge (see Nikander 2008). A bilingual (Finnish-English) translator has checked the translations.

A detailed examination of the connective and repetitive features of the talk revealed that notions of a municipality's role as service organiser and provider comprise an essential aspect of the discussion of the various subsidy systems. Based on this finding, we were able to identify three frames within which public support for private ECEC was rationalised. In each frame, the municipality's relationship to private provision and is considered from a different viewpoint. The three frames are the pragmatic frame, government frame and choice frame. However, these three frames are not mutually exclusive but often overlap and intertwine.

\section{Pragmatic frame}

The pragmatic frame implies that increasing public support for private provision is a costefficient way to produce ECEC services, to respond to fluctuating service demand and to solve issues concerning investments in ECEC infrastructure. In this approach, the role of the municipality as an ECEC provider is hence constructed in relation to its statutory obligations, the demand for ECEC services and the economic realities presented in the discussion. Typically, the increased dependence on the private ECEC sector is represented as a pragmatic progression, without linking it to any political viewpoints or ideals. It is represented as independent of the 'personal' viewpoints that the interviewees express ${ }^{4}$. More pronounced accounts represent public support for private provision as a necessity that will allow economic leeway for a municipality facing financial hardship or increased ECEC demand. Excerpt 1 demonstrates how this necessity is constructed.

\section{Excerpt 1 (Administrator)}

1 ...The same [private] entrepreneur [subsidised with vouchers] has just started work on a new

2 branch (...) to help improve our day care situation. At the moment we've got temporary

3 premises and the situation we have is that we don't, the municipal authority doesn't really

4 have any vacancies of its own. Our options are either to start building our own day care

5 centre, there was some talk to that end during the previous council's term, and we actually

6 have the blueprints and so on. But in the end it was not felt... felt that this was a good option

\footnotetext{
${ }^{4}$ The data implies a sort of political consensus about public support for private ECEC provision at the local level. This is visible, for example, in the way that interviewees justify and accept local developments even if they contradict the party's national policies. The administrators, for their part, described the daily practices and the situation of local ECEC in more detail and more comprehensively than politicians, but nonetheless drew on the same discourses as the politicians in their accounts.
} 
7 and at the moment we've had some major school renovations underway and they've been 8 given priority. In that sense it was really good that a private provider took over and we had 9 these discussion that they'll commission the development of a new day care centre, which will

10 allow us to offload some of these temporary premises.

The interviewee refers to the challenging reality within which the decisions about ECEC in the municipality are made: a shortage of ECEC services and premises, as well as investments in school buildings used for compulsory education ${ }^{5}$. In this situation, the private ECEC provider is represented as the municipality's helper because it takes charge of the investments in ECEC infrastructure. Excerpt 1, therefore, demonstrates how the necessity of investment in ECEC infrastructure translates into the necessity of implementing private ECEC provision with the help of public subsidies.

While viewing private ECEC as a necessity for the municipality, the interviewees also describe the increase in private provision as an economically rational policy, as illustrated in Excerpt 2.

\section{Excerpt 2 (Politician)}

1 So cost-efficiency is what is looked for when private providers get involved and whether the 2 private sector can deliver greater economy, that remains to be seen. But there are lots of 3 examples that they've done just that in other areas. This of course is the national policy that all 4 citizens have access to services so that they're provided almost by anyone. It's the individual's 5 choice and that's expected to produce greater efficiency in service provision. The same goes for

6 ECEC, better results with less financial input.

The interviewee represents private ECEC provision as cost-effective by referring to experiences in other service sectors and a national multi-provision trend (lines 2-4). Here, individual freedom of choice, enabled by a multi-provision model, is seen as enhancing the efficiency of services in general, as well as in ECEC specifically. Supporting private ECEC provision is thus represented as a rational development leading to better outcomes for the services, with fewer resources being consumed. By using passive voice (lines 1, 2, 4, 5) and speculative utterances (lines 2, 5), the interviewee avoids explicitly positioning himself related to the topic. This analytical mode represents private provision as a result of rational contemplation that is free of political and personal ideals. Thus, private ECEC provision and economic support for such are viewed as a pragmatic solution given the situation at hand. Elsewhere in the data, pragmatism is produced, for example, by underscoring the fact that although privatisation is not in line with interviewee's own ideology, supporting it is an economic necessity. Pragmatism can be constructed also by presenting doubts and contradictions related to privatisation and its' actual cost-effectiveness.

\section{Government frame}

The government frame consists of talk that addresses the relationship between public sector and private ECEC provision. Private provision may be positioned in a complementary role or as a part of the public ECEC network. These two ways of representing the public-private

\footnotetext{
${ }^{5}$ In Finland, the provision of primary and secondary education is statutorily, a public responsibility.
} 
relationship differ from each other in terms of the aspects of governance, regulation and control. The way in which this relationship is represented appears to be connected to the private sector's share of a municipality's ECEC provision and the features of the local subsidy system.

When the interviewees rationalise the PDAMS system, the private sector, as a provider, is typically positioned, as Excerpt 3 illustrates, in a complementary position relative to public ECEC provision.

\section{Excerpt 3 (Politician)}

1 Well they do pay some municipal supplement [on top of PDA] so that people can afford to send

2 their kids [ to a private ECEC centre] if public day care is not available (...) but they do work

3 together, I mean their existence is really appreciated and absolutely they're like a partner.

In Excerpt 3, the interviewee states that the municipal supplement (MS) enables families to use private ECEC services if public services are not available. The use of the subordinating conjunction if positions private provision in a secondary role and public provision in a primary role as ECEC providers. Public-private relationship is thus represented as hierarchical, but the line between the sectors is blurred by underscoring collaboration with and appreciation for private provision (line 3). Throughout the data, the interviewees emphasise collaboration between the sectors, though the element of sparring in private provision is explicated in some accounts.

The PDAMS system is not typically rationalised as an instrument of control, regulation or governance regarding private ECEC provision. In fact, the interviewees from municipalities that have begun to provide ECEC vouchers alongside the PDAMS system might state that private providers may choose to stay with the PDAMS system when they are not willing or capable of accepting the terms of the local voucher contract and the municipal control it implies. In addition, PDAMS is connected to private providers' opportunity to freely price their services.

Thus, the relationship between the municipality and private ECEC provision follows a different logic when the interviewees describe the ECEC voucher system. First, the regulation and governance of the private sector are emphasised; second, private provision is often aligned with public provision and presented as a part of the same service system. Typically, this is done by underscoring 'uniformity' between the sectors, as Excerpt 4 illustrates.

\section{Excerpt 4 (Administrator)}

1 It's just plain ordinary families [who use private services], I mean we refer more families with

2 children than there are those who apply out of their own accord. Oppila [name of the provider]

3 has worked closely with them in the sense that they're committed to the same objectives and

4 rules and ways of working as we are [public ECEC], and because it's this income-tested

5 voucher system which is not intended only for certain families, but anyone is eligible to apply

6 or we can refer anyone, it appears as exactly the same kind of service as all our other services.

In Excerpt 4, the uniformity of public and private ECEC is produced by highlighting their similarities from the families' and municipality's perspectives and by illustrating a close collaboration (lines 1,2) and consistent course of action (line 3 ) between the sectors. The 
interviewee emphasises the evenness of public and private provision in utterances like 'plain ordinary' (line 1) and 'exactly the same kind' (line 6). In sum, by underlining the uniformity of public and private ECEC provision, the interviewee depicts private services as though they were part of the municipality's service provision and not a separate service sector.

Highlighting similarities is a typical way of positioning private provision as aligned with public provision in municipalities that provide vouchers.

But not all interviewees accept the premise that private and public ECEC provision are equal and uniform. Instead, it is argued that some private providers tend to choose their customers. The voucher system is described as an instrument that is used to steer private providers in a desired direction and so to guarantee the similarity and equality of public and private provision, for instance in terms of the availability of special support. Private providers are thus represented as economically rational actors who can be controlled by financial incentives. Moreover, private providers' reliance on public subsidies is produced, for example, in accounts of negotiations about the value of local vouchers. This reliance constructs an asymmetric power relationship between public ECEC administration and private providers because the former has control over the cash flows on which the latter depend. The income tested voucher system is hence represented as an instrument that positions private ECEC both as a part of the municipality's service portfolio and in a subordinate relationship as compared to the administration of public ECEC. Nevertheless, in municipalities where private provision already has a notable foothold, private providers are represented as having significant power resources as well. These power resources are produced with the following logic: the more the private providers' share of service provision in the municipality increases, the more the municipal ECEC administration will be forced to consider these private providers' standpoints.

Though increasing private provision is often represented in a positive tone, the risks of this development are explicated as well.

\section{Excerpt 5 (Politican)}

1 Of course there's the risk [in providing vouchers], which we did recognize, that when you're

2 creating markets you will see all flowers blooming for a while and you'll get new and local

3 service providers. But there is this risk of concentration and a major operator buying them all

4 out, in which case you'll soon be left with not many service providers after all, so again

5 you'll be faced with this pricing issue and what have you. So again just one or two providers

6 will be calling the shots, so I mean for me, this is something you have to be wary about. For

7 me, we should have both local, association-based providers as well as business operators.

7 They should all have the chance to get involved. But if you have just one or two providers

8 running the whole day care business in the city, that in my opinion isn't a good place to be in

9 because you have to remember that they, if they're limited companies following the rules of

10 normal market economy, then it definitely has, especially if it's backed by some multinational

11 investment group, then it will have certain specified yield requirements and that's at the

12 expense of something else. (...) But I do think that this [private provision] is necessary, I

13 mean it's a good servant but a bad master and you need to make sure it doesn't get too much

14 power.

Excerpt 5 demonstrates the contradictory web of meanings connected to publicly subsidised ECEC markets. Though the diverse forms of private provision are represented as worth pursuing (lines $6-8,12$ ), the consolidation of private provision is represented as an 
avoidable form of progress by linking it to the increased pricing (lines $3-5$ ) power of private providers; large corporations' determined profit seeking, which restricts resourcing in 'something else' (lines $11-12$ ), and the increasing power of private ECEC in relation to municipal administration (lines 12 - 14). Throughout the entire account, especially when using the idiom of good master and bad servants (lines 13 -14), the interviewee legitimises the municipality's need to control and regulate privatisation development and also represents the multi-provision model of ECEC as desirable.

In sum, the voucher system is represented as an instrument that enables municipalities to control the size of the private sector. The ECEC voucher is seen both as a subsidy via which private provision can be increased in the municipality and as a means of restricting the share of private ECEC in the municipality when needed. Thus, the voucher system is rationalised as an instrument via which private provision can be adapted to meet the fluctuating demand for ECEC services. The terms of the local voucher contract are represented as a mechanism via which the private sector can be governed, controlled and regulated by the municipal ECEC administration.

\section{Choice frame}

The choice frame comprises interview discussions that consider the municipality's role in families' ECEC choices. The key notion of the approach is that increasing private provision affords all families greater freedom to decide about their children's ECEC. More precisely, this approach is comprised of accounts that consider private provision as an improvement to the municipality's ECEC service selection and discuss its affordability for families and their access to private services.

One aspect of the frame represents private provision as an improvement in the municipality's service selection, which thus enables the local ECEC system to better serve families. This is demonstrated in the following excerpt, in which the interviewee describes the benefits of private provision.

\section{Excerpt 6 (Administrator)}

1 I'm sure that from the child's and family's point of view it's having a choice. Perhaps

2 being able to make the best possible choice based on the family's and the child's needs,

3 it gives that freedom of choice.

The interviewee underscores both the family's and the child's interests and needs in the selection of ECEC. In her response, the possibility of choosing the best ECEC provider for the child and the family is linked with the existence of private provision. Elsewhere in the data, the interviewees sometimes associate private provision's ability to meet families' needs with specific pedagogical approaches that private providers may follow. Such diversity in ECEC services is equated with quality service selection. For example, in Excerpt 6, the interviewees implicitly position the parents as responsible for their ECEC choices while underscoring the possibility of each parent choosing the best services for their child and family. Moreover, the municipalities' economic support for private provision is usually represented as in the interest of the families. 
Another aspect of the frame relates to both families' financial opportunities to choose a satisfactory provider and affordability of private provision. The significance of this aspect of this approach is evident because the interviewees often, either implicitly or explicitly, account for it, even although they were not asked about it. Different subsidy systems are rationalised using different logics regarding the affordability of the services.

\section{Excerpt 7 (Administrator)}

$1 \quad Q:$ What was the reason why you decided to switch to this voucher system [income-tested]?

2 A: We wanted it [private ECEC] to give families equal... the option. Private day care

3 allowances make day care so expensive that it hasn't been a real option for all families. So here

4 [the voucher system] we're looking at giving everyone the opportunity to apply [for private

5 ECEC].

As Excerpt 7 shows, the interviewee explains that the income-tested voucher system was introduced in the municipality because it provides equal economic opportunities for every family to apply for private ECEC services (lines 2, 4). Moreover, the interviewee associates the PDAMS system with the selectivity of private ECEC (lines 2, 3). Hence, it appears that affordability and selectivity are understood as opposite sides of same coin regarding the price of customer fees. The municipality is represented as a responsible actor, serving families and allowing them to choose the services they want.

Indeed, the voucher system is specifically justified by stating that it enables private ECEC for all families, regardless of socio-economic situation. This is also demonstrated in Excerpt 8.

\section{Excerpt 8 (Administrator)}

1 As for the voucher system, what we've been aiming to do with our planning and development

2 efforts is precisely to achieve equality among all local residents. We've not wanted to create an

3 elite day care centre, but precisely to [provide services] for everyone on an equal basis.

Above, the interviewee represents the voucher system as an instrument that guarantees equality among local residents. Equality is implicitly connected with the affordability of private ECEC when the interviewee responds to an alleged selectivity accusation by underscoring the fact that the municipality's purpose is to develop not an elite day care centre but a centre that is equally just for everyone (lines 2, 3). For example, in Excerpt 8, the affordability of private ECEC, irrespective of a family's socio-economic situation, is particularly connected to the voucher system, and it is also repeatedly produced in the data as a precondition for equality among local families.

The PDAMS system, especially fixed-sum, is usually associated with the selection of client families for private ECEC based on their financial resources. The selectivity is also used as a justification for the municipality's decision to change its subsidy system from PDAMS to a voucher. Excerpt 9 demonstrates the logic by which the PDAMS system and selectivity are related to one another.

\section{Excerpt 9 (Administrator)}

$1 \quad$ Private provision is brought alongside the service network as a complementary service (...)

2 And the private provider then sets the customer fees so that they can maintain their own

3 customer base, looking at what kind of customer fees they can charge. But in the planning and 
4 preparation process, we haven't started out from the concept that you see in so many voucher

5 systems that the fees [for private ECEC] have to be exactly the same [as for public ECEC]

6 (...) And as we haven't even started out from the idea that it should be priced at the exact same

7 level. Yes of course in some cases it will cost a little bit more to families.

In Excerpt 9, the interviewee explicitly positions private ECEC provision as complementing public ECEC provision. Regarding private providers' ability to select clientele, the interviewee describes the freedom of private providers to set their own (higher) customer fees. The account thus separates the municipality from the governance of the private sector and draw on market logic, according to which the prices of ECEC services are negotiated between customers and providers. Thus, market logic is used to implicitly legitimise the selectivity of private providers.

Families' subject positions are constructed differently in the two subsidy systems. Regarding both vouchers and PDAMS, parents and families are considered active subjects who are free to decide about and choose their child's care and education. However, the accounts that promote the voucher system underscore the equality of families in ECEC selection, which is safeguarded by the municipal subsidy policy. When discussing the PDAMS system, parents and families are described as individual subjects or clients who act independently on the ECEC markets. The latter notion includes though the possibility that the family's freedom of choice may be limited due to the pricing of the customer fees for private ECEC.

\section{Conclusion}

In this article, we have identified three frames within which public subsidies (vouchers and PDAMS) for private ECEC and ECEC privatisation are rationalised: the pragmatic frame, government frame and choice frame. The pragmatic frame is constructed by representing publicly subsidised increases in private ECEC as an economically rational, pragmatic or necessary method of development. The government frame includes two ways of producing the public-private relationship. The first positions private provision as part of the public service network and presents municipal ECEC administration as occupying a power position and being in charge of the control, regulation and government of private provision. The second positions private ECEC in a complementary role and as a separate sector by drawing a line between the public and private sectors, emphasising the public sector's role as the main provider of ECEC and allowing more space for market mechanisms at the expense of public involvement. The choice frame is related to the government frame such that when private provision is positioned as a part of the public ECEC system, the affordability of private ECEC and thus every family's equal opportunity of choice is emphasised. When private provision is positioned in a complementary role, families are represented as active market agents, with the result that the selectivity of private ECEC becomes implicitly accepted.

The results show how the rationalisations within the frames function to facilitate the privatisation and marketisation of ECEC. At the same time, the results imply that municipalities primarily endeavour to keep ECEC provision under their own control, as suggested by Foucauldian thinking which argues that in contemporary neoliberal governance markets are constituted and maintained by states (Gane, 2012). 
This study also suggests that the neoliberal market rationality presented in the previous literature (e.g.Brennan et al., 2012; Moss, 2009; Naumann, 2011; Penn, 2009, 2012), as reflected in ideas such as freedom of choice, economic effectiveness and quality due to competition, represents an important resource for the interviewees to use in legitimising and accounting for municipal ECEC policies related to private provision. However, the perceived importance of the equality and affordability of private ECEC for all families can be understood as a heritage of the ideas of universalism, on which Finnish ECEC institutions have been based. The intertwinement of market rationality and universalism can be related to Naumann's (2011) observations suggesting that ECEC policies, which are shaped by historical trajectories, do not evolve from one paradigm or regime to another as such. Rather, the process can be understood as the maturation of 'old' welfare-state promises and also as searching for new paths (see also Mahon et al., 2012). In the Finnish context, this process becomes especially visible in the way in which publicly financed, regulated and governed private ECEC is constructed as a part of public ECEC network in the accounts analysed. The old promises of universalism are still involved even as new paths, such as market rationality, are used to justify ongoing developments.

The findings of this study imply that the concept of equality in the context of ECEC may be shifting from a universal conception which emphasizes families' universal right to public ECEC of uniform quality towards families' equal opportunity to choose the services they want to use. Parents are thus constructed, using Yuen and Grieshaber's (2009) conceptualisation, as well-informed consumers bearing the risk and responsibility of making successful choices for their children. Furthermore, the choices made by parents can thus be understood as acts of moral accountability (Karlsson, Löfdahl, \& Prieto, 2013).

Conceptualising equality of ECEC access in terms of equal opportunities to choose emphasizes the equal distribution of ECEC. However, this notion can be problematic from a social justice point of view. If social justice is understood as 'a strong equality of opportunity among individuals', it is clearly inadequate to focus only on different distributive patterns. Instead, we must also intervene in the institutional and individual-level processes and interactions which maintain structural inequalities and constrain equal opportunities (Young, 2001). Fraser's (1998) dual framework of justice likewise includes both economic redistribution and cultural recognition. Moreover, as Lazenby (2016) argues, in addition to concentrating on equal distribution, the profound conception of equality of opportunity in education requires making a distinction between equality of opportunity through and for education where through refers to the instrumental value and for to the intrinsic value of education. Therefore, as Connel argues (2012), future discussions about the marketisation of ECEC should recognize that social justice in education is not just about the equal distribution (access) of educational services but about the nature of the service itself, and its consequences for society over time as well.

In sum, this article has shown that the meanings and ideas used to rationalise the marketisation of Finnish ECEC give a contradictory and inconsistent picture of this process. Even though market logics and tendencies seem to have gained a strong foothold in local policies, there is a firm commitment to universalism and maintaining public control over 
local ECEC provision. An interesting and important question for future research is to explore the evolution of the relationship between private providers, which increasingly often are consist large corporations, and municipal control and governance.

\section{References}

Adamson, E., \& Brennan, D. 2014. "Social Investment or Private Profit? Diverging Notions of 'Investment' in Early Childhood Education and Care." International Journal of Early Childhood 46 (1): 47-61.

Angus, L. 2015. "School choice: neoliberal education policy and imagined futures." British Journal of Sociology of Education. 36 (3): 395-413.

Akgunduz, Y. E., \& Plantega, J. 2014. "Childcare in the Netherlands: Lessons in privatisation." European Early Childhood Education Research Journal 22 (3): 379_ 385.

Alvesson, M., \& Karreman, D. 2000. "Varieties of Discourse: On the Study of Organizations through Discourse Analysis." Human Relations 53 (9), 1125-1149.

Anttonen, A. \& Meagher, G. 2013. Mapping marketisation: concepts and goal. In Marketisation in Nordic eldercare: a research report on legislation, oversight, extent and consequences, edited by G. Meagher \& M. Szebehely, 13-22. Stockholm Studies in Social Work 30. Stockholm: Stockholm University.

Brancaleone, D \& O'Brien, S. 2011. "Educational commodification and the (economic) sign value of learning outcomes." British Journal of Sociology of Education 32 (4): 501519.

Brennan, D., Cass, B., Himmelweit, S., \& Szebehely, M. 2012. "The marketisation of care: Rationales and consequences in Nordic and liberal care regimes." Journal of European Social Policy 22 (4): 377-391.

Çalışkan, K \& Callon, M. 2010. "Economization, part 2: a research programme for the study of markets." Economy and Society. 39 (1): 1-32.

Connell, R. 2012. "Just education." Journal of Education Policy, 27 (5): 681-683

Djelic, M.-L. 2006. "Marketization: from intellectual agenda to global policy-making", in), Transnational Governance: Institutional Dynamics of Regulation. Edited by Djelic, M.-L.and Sahlin-Andersson, K, 53 - 73. Cambridge: Cambridge University Press.

Finnish National Agency For Education, FNAFE 2018. Early Childhood Education and Care. https://www.oph.fi/english/education system/early childhood education 20.10.2018

Fraser, N. 1998. "From Redistribution to Recognition? Dilemmas of Justice in a 'PostSocialist Age'." Feminism \& Politics, edited by Phillips, A. Oxford University Press, Oxford, 430-460.

Gane, N. 2012. "The governmentalities of neoliberalism: panopticism, post-panopticism and beyond." The Sociological Review 60: 611-634.

Gobo, G. 2004. Sampling, Representativeness and Generalizability. In, Qualitative Research Practice, edited by C. Seale, G. Gobo, J. F. Gubrium, \& D. Silverman London, 435456: SAGE Publications.

Hansen, M. \& Lindholst, A. 2016. "Marketization revisited." International Journal of Public Sector Management, Vol. 29 Issue: 5, pp.398-408, https://doi.org/10.1108/IJPSM-052016-0090 
Heracleous, L. T. 2004, Interpretivist Approaches to Organizational Discourse, in. The SAGE Handbook of Organizational Discourse, edited by Grant, D., Hardy, C., Oswick, C. \& Putnam, L, 175 - 192. London: SAGE Publications Ltd.

Karlsson, M., Löfdahl, A., \& Prieto, H. P. 2013.'Morality in parents' stories of preschool choice: narrating identity positions of good parenting", British Journal of Sociology of Education 34 (2): 208-224.

Kildal, N. \& Kuhnle, S. 2005. "The Nordic welfare model and the idea of universalism." In Normative Foundations of the Welfare State: The Nordic Experience, edited by Kildal, N. \& Kuhnle, S. 13-33. London: Routledge.

Lahtinen, J., \& Selkee, J. 2016. "Varhaiskasvatuskyselyraportti II: hallinto, kuntalisät, palveluseteli." Helsinki: Kuntaliitto.

Lazenby, H. 2016. "What is equality of opportunity in education?" Theory and Research in Education 14 (1): 65-76.

Lewis, J., \& West, A. 2016. "Early Childhood Education and Care in England under Austerity: Continuity or Change in Political Ideas, Policy Goals, Availability, Affordability and Quality in a Childcare Market?’ Journal of Social Policy 46 (2): 118.

Lloyd, E., \& Penn, H. 2014. "Childcare markets in an age of austerity." European Early Childhood Education Research Journal 22 (3): 386-396

Mahon, R., Anttonen, A., Bergqvist, C., Brennan, D., \& Hobson, B. 2012. "Convergent care regimes? Childcare arrangements in Australia, Canada, Finland and Sweden." Journal of European Social Policy 22 (4): 419-431.

MoF, Finnish Ministry of Finance. 2018. https://vm.fi/en/local-government-affairs 20.10.2018.

Moss, P. 2009. “There Are Alternatives! Markets and Democratic Experimentalism in Early Childhood Education and Care." Working Papers in Early Childhood Development, Number 53.

Naumann, I. 2011. "Towards the marketization of early childhood education and care? Recent developments in Sweden and the United Kingdom." Nordic Journal of Social Research 2 (2): 37-53.

Nikander, P. 2012. Interviews as discourse data. in The SAGE Handbook of Interview Research: The Complexity of the Craft ( 2 ed.), edited by J. Gubrium, J. Holstein, A. Marvasti, \& K. McKinney, 397-414. Thousand Oaks: California: SAGE Publications, Inc.

Nikander, P. 2008. Working with Transcriptions and Translated Data. Qualitative Research in Psychology, 5: 3, 225-231. Special issue on Teaching Qualitative Methods.

Ozga, J. 2011. “Governing Narratives: 'Local' Meanings and Globalising Education Policy." Education Inquiry 2 (2): 305-318.

Penn, H. 2000. "Policy and Practice in Childcare and Nursery Education." Journal of Social Policy 29 (1): 37-54.

Penn, H. 2009. 'International Perspectives on Quality in Mixed Economies of Childcare', The National Institute Economic Review 207 (1): 83-89.

Penn, H. 2011. "Gambling on the Market: The Role of For-Profit Provision in Early Childhood Education and Care." Journal of Early Childhood Research 9 (2): 150-16.

Penn, H. 2012. Childcare markets: do they work? In Childcare markets: Can they deliver an equitable service?, edited by Lloyd, E \& Penn, H, 19-42. Bristol: Policy Press.

Phillips, N., \& Hardy, C. 2002. "Discourse Analysis: Investigating Processes of Social Construction.” Sage University Papers Series on Qualitative Research Methods, Vol. 50, Thousand Oaks, CA: Sage. 
Potter, J. 2004. "Discourse analysis as a way of analysing naturally occurring talk." In Qualitative research: Theory, method and practice, edited by Silverman, D. 187-207. London: Sage.

Potter, J. 2012. "Discursive psychology and discourse analysis." In The Routledge Handbook of Discourse Analysis, Edited by Gee, J. P. \& Handford, M. 104-119. Routledge Ltd M.U.A.

Potter, J., \& Wetherell, M. 1995. “Discourse analysis.” In Rethinking methods in psychology, edited by Smith, J.A., Harré, R. \& Van Langenhove, L.80-92. London: SAGE Publications Ltd.

Schimank, U. \& Volkmann, U. 2012. "Economizing and Marketization in a Functionally Differentiated Capitalist Society - A Theoretical Conceptualization." in The Marketization of Society: Economizing the Non-Economic. Edited by Schimank, U. \& Volkmann U.; Published 2012; Bremen: Research Cluster "Welfare Societies".

Schwiter, K., Berndt, C. \& Truong, J. 2015. "Neoliberal austerity and the marketisation of elderly care." Social \& Cultural Geography, 19 (3): 379-399.

Säkkinen, S., \& Kuoppala, T. 2017. "Varhaiskasvatus 2016.” THL:n tilastoraportti 29/2017.

Wadsworth, J., \& George, R. 2009. "Choosing the Right Approach: New Labour and the care and education of young children." FORUM 51 (3): 309-318.

Vanderbroeck, M. 2006. "Globalisation and Privatisation: The Impact on Childcare Policy and Practice." Working Papers in Early Childhood Development, No. 38.

West, A. \& Nikolai, R. 2013. "Welfare Regimes and Education Regimes: Equality of Opportunity and Expenditure in the EU (and US)", Journal of Social Policy 42 (3): 469-493.

Vincent, C., Braun, A. \& Ball, S. 2008. "Childcare, choice and social class: Caring for young children in the UK." Critical Social Policy 28 (1): 5-26.

Vlasov, J. 2018. "Reflecting Changes in Early Childhood Education in the USA, Russia and Finland." Academic dissertation. Acta Universitatis Tamperensis 2416.

Young, I. 2001. "Equality of Whom? Social Groups and Judgments of Injustice." The Journal of Political Philosophy. 9 (1): 1-18.

Yuen, G., \& Grieshaber, S. 2009. "Parents' Choice of Early Childhood Education Services in Hong Kong: A Pilot Study about Vouchers." Contemporary Issues in Early Childhood 10 (3): 263-279.

Transcription key:

(...) excluded section

[ ] Author's comment

... sentence is not completed, address continues 